\title{
El populismo como amenaza a la Democracia: un análisis de la Carta Democrática Interamericana
}

\section{Populism as a Threat to Democracy: an Analysis of the Inter-American Democratic}

Marcelo Alberto López Alfonsín http://orcid.org/0000-0002-2110-3354

María Sol Bucetto http://orcid.org/0000-0003-4215-3913

http://dx.doi.org/10.21503/lex.v19i28.2314

* Juez de la Ciudad Autónoma de Buenos Aires (Argentina). Doctor en Derecho, Área Derecho Constitucional, (Universidad de Buenos Aires). Magíster en Derecho Ambiental (Universidad de Lomas de Zamora). Argentina.

Correo electrónico: mlalfonsin@jusbaires.gov.ar

** Abogada UBA. Candidata a magíster en Derechos Humanos, Universidad Nacional de La Plata. Docente de "Los derechos humanos en la Constitución Nacional", Universidad de Buenos Aires.

Correo electrónico: solbucetto@yahoo.com.ar
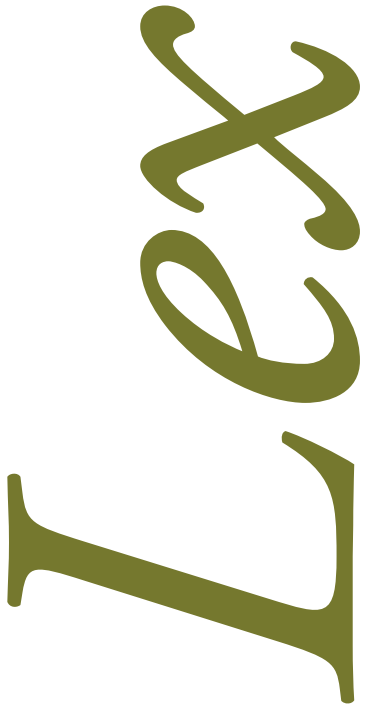


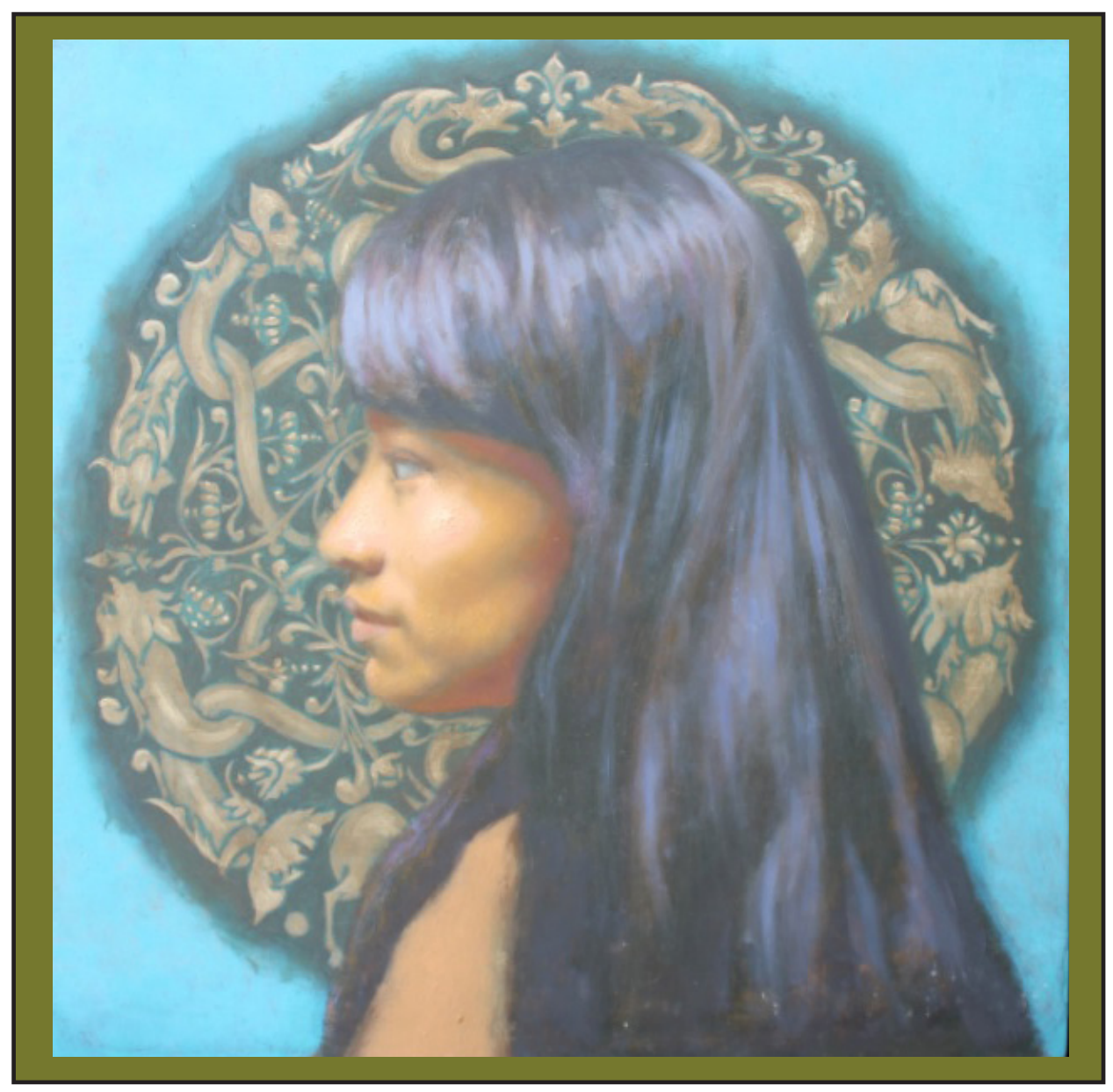

La Shipiba. Óleo sobre madera 31 x $31 \mathrm{~cm}$.

David Hewson (EEUU, 1966)

www.davidhewsonart.com 


\section{RESUMEN}

La promoción de la democracia ha sido una de las principales misiones del sistema interamericano de derechos humanos. En este sentido, la adopción de la Carta Democrática Interamericana constituye un hito a razón de que representa la síntesis de una serie de mecanismos jurídicos y diplo $\neg$ máticos que los Estados miembros fueron desarrollando y proporciona una herramienta valiosa para la defensa colectiva del sistema democrático. Sin embargo, en la actualidad uno de los desafíos de los sistemas regionales es el populismo autoritario que socava la esencia institucional y la calidad de la democracia. Es posible observar que, hasta el momento, las respuestas de la OEA ante situaciones de amenaza del orden constitucional han sido firmes, pero han fallado en reaccionar cuando los presidentes han utilizado los mecanismos democráticos formales para concentrar el poder.

Palabras clave: democracia, populismo, Carta Democrática Interamericana.

\section{ABSTRACT}

The promotion of democracy has been one of the main missions of the inter-American human rights system. In this sense, the adoption of the Inter-American Democratic Charter constitutes a milestone, as it represents the synthesis of a series of juridical and diplomatic mechanisms that the member states had developed and provides a valuable tool for the collective defense of the democratic system. However, one of the challenges for regional systems today is authoritarian populism that undermines the institutional essence and quality of democracy. It is possible to observe that, up to now, the OAS responses to situations of threat to the constitutional order have been firm, but they have failed to react when presidents have used formal democratic mechanisms to concentrate power.

Key words: democracy, populism, Inter-American Democratic Charter. 


\section{INTRODUCCIÓN}

El contexto histórico que circundó la creación de la Organiząción de Estados Americanos propició que durante los primeros treinta años exista una convivencia entre regíme $\neg$ nes dictatoriales, militares, autoritarios, semidemocráticos y democráticos. Sin perjuicio de ello, el sistema interamericano desde sus orígenes se ha impuesto forjar la democracia allí donde no existe, fortalecerla donde se instala y defenderla donde alcanza su consolidación y madurez ${ }^{1}$.

Las menciones a la democracia se encuentran en una gran cantidad de instrumentos del sistema interamericano, tales como la Carta fundacional de la Organización de 1948 y las referencias al sistema democrático como el único que valida la protección de los derechos humanos en la Convención Americana de Derechos Humanos. A tal punto ha florecido esta concepción en el ámbito interamericano que se ha llegado a conformar un derecho humano a la democracia. En palabras de Aguiar, antiguo juez de la Corte Interamericana de Derechos Humanos, estamos en presencia de un derecho humano que "es [...] conceptualmente, un verdadero derecho humano transversal: derecho humano de base que determina el contexto en defecto del cual los mismos derechos humanos carecerían de sentido; y ajusta determinándolo, por ende, el sentido último de la organización constitucional y del funcionamiento mismo de la democracia como garantía de éstos"2.

Más allá de la profusa documentación doctrinaria por parte de los operadores del sistema, nunca se desarrolló en demasía el concepto de sistema democrático. A razón de ello, en los años ' 80 y '90 se llevó a cabo un largo debate en el seno de la Organización respecto a la necesidad de plasmar en instrumentos jurídicos su intención de promover y consolidar la democracia representativa -dentro del respeto al principio de no-intervención-. En el marco de esta misión, en el año 2000, el Fujigolpe en Perú marcó el final de una etapa y dio

1. Asdrúbal Aguiar, Calidad de la democracia y expansión de los derechos humano. Cuadernos de la Cátedra Mezerhane sobre Democracia, Estado de Derecho y Derechos Humanos (Caracas: Editorial Jurídica Venezolana, 2018), p. 22.

2. Asdrúbal Aguiar, El derecho a la democracia. La democracia en el derecho y la jurisprudencia interamericanos. La libertad de expresión, piedra angular de la democracia (Caracas: Editorial Jurídica Venezolana, 2008), p. 55. 
lugar al nacimiento de la Carta Democrática Interamericana como síntesis de una serie de mecanismos jurídicos y diplomáticos que los Estados miembros fueron desarrollando en el sistema interamericano, tales como la modificación de la Carta Constitutiva de la OEA.

Pese a su loable finalidad, la Carta Democrática Interamericana goza de escasa popularidad y ello quizá se deba a la combinación de dos factores de distinta índole: por un lado, su desafortunada concomitancia con los sucesos de impacto mundial que afectaron a los Estados Unidos el 11 de septiembre de 2001; por el otro, su disímil naturaleza jurídica respecto a los demás instrumentos del sistema internacional de protección de los derechos humanos.

No obstante, sin dejar de considerar la conmoción que el ataque terrorista generó en la comunidad internacional y sin perder de vista que la Carta Democrática es, efectivamente, un instrumento político que dista de contener disposiciones similares a las previstas en las convenciones y tratados, su valor no debe pasar inadvertido, toda vez que erige una señal clara y una advertencia de que si en alguno de nuestros Estados se pone en peligro el sistema democrático de gobierno, existe un plan colectivo para responder de manera contundente ${ }^{3}$.

De este modo, la Carta representa una innovación en el sentido que en ella la defensa y promoción de la democracia ya no es algo que queda bajo la soberanía absoluta de los Estados miembros de la OEA, y en ciertas condiciones se pueden invocar los mecanismos internacionales para su protección colectiva. Sin embargo, el consenso democrático está siendo socavado por nuevas amenazas como el autoritarismo selectivo, la polarización política y los golpes de Estado. La Carta Democrática sólo ha respondido a este último desafío, mientras que tiende a ignorar las amenazas que surgen desde los propios gobiernos ${ }^{4}$.

En la actualidad, uno de los desafíos de los sistemas regionales es el populismo autoritario que socava la esencia institucional y la calidad de la democracia, a través de la represión selectiva de la oposición, violaciones de derechos humanos, censura y la eliminación de la separación de poderes. Esta distorsión sistémica también incorpora el uso y abuso de los recursos del Estado en favor del candidato del gobierno de turno, incluyendo el financiamiento directo o en especie de la campańa; la distribución paternalista/clientelista de beneficios sociales por razones proselitistas, que solo crean dependencia; el reparto pre-comicios de bienes de consumo doméstico; la inauguración de obras públicas que nunca se finalizan; la adquisición y control de medios de comunicación por el gobierno o aliados, que se utilizan para proselitismo

3. Cfr. Palabras del Secretario General César Gaviria ante la sesión protocolaria del Consejo Permanente del 16 de septiembre de 2002.

4. Susanne Gratius, “Diez años de la Carta Democrática Interamericana”, FRIDE, Policy Brief № 61, septiembre 2011, acceso el 15 de enero de 2021

https://www.flacsoandes.edu.ec/sites/default/files/agora/files/1328286471.pb_61_carta_democratica_ interamericana_1_.pdf, p. 1. 
electoral y gubernamental, acompañado del amedrentamiento y discriminación de medios independientes, la persecución política de los opositores al régimen, entre otros ${ }^{5}$.

En este marco, en el presente artículo nos proponemos analizar la progresiva recepción por parte del Sistema Interamericano de la democracia representativa como un principio aceptado por todos los Estados miembros y cómo ello influyó en el proceso de confección de un instrumento cuya aspiración fuera responder rápida y colectivamente en defensa de la democracia. Asimismo, nos referiremos a los casos en los que la OEA ha hecho uso de la Carta Democrática para reestablecer el orden democrático y cómo -si es que ha sucedido- ha hecho frente a los autoritarismos personalistas o neopopulismos que han sido mencionados como fenómenos de actualidad.

\section{LA CARTA DEMOCRÁTICA INTERAMERICANA}

\subsection{Antecedentes y contenido}

Como adelantamos en el apartado anterior, la proclamación de la Carta Democrática Interamericana representa la síntesis y sistematización de un largo proceso de construcción del régimen de promoción de la democracia a nivel regional que se manifestó tanto en las sesiones de la Asamblea General como en el Consejo Permanente de la OEA, junto con la participación de los Jefes de Estado en las diferentes Cumbres que se desarrollaron a fin de buscar formas de consolidar y fortalecer la capacidad de la OEA de responder a las amenazas al orden democrático.

De este modo, además de la proclamación de la democracia como condición indispensable para la estabilidad, la paz y el desarrollo de la región en el Preámbulo de la Carta de la OEA, la Declaración Americana de los Derechos y Deberes del Hombre y la Convención Americana sobre Derechos Humanos contienen los valores y principios de libertad, igualdad y justicia social que son intrínsecos a la democracia.

En cuanto a la actuación de la Asamblea General, es importante resaltar la Resolución Derechos Humanos y Observación Electoral de 1989 que encomienda al Secretario General que organice observaciones electorales en los países que lo solici-ten. Siguiendo esta iniciativa, en la Asamblea realizada en 1991 en Santiago de Chile, se reiteró el compromiso de actuar colectiva e inmediatamente para proteger la democracia cuando esta se vea amenazada en cualquier Estado miembro y se adoptó la renombrada Resolución 1080 (Democracia representativa), a través de la cual se estableció un mecanismo de acción colectiva en caso de que se produjera una interrupción abrupta o irregular del proceso político institucional

5. Rubén Perina, "Los desafíos de la Carta Democrática Interamericana”, Estudios Internacionales, n 173 (2012), pp. 7-36, p. 12. 
democrático o del legítimo ejercicio del poder por un gobierno democráticamente electo en cualquiera de los Estados Miembros de la Organización.

A fin de complementar y ejecutar lo previsto en la Resolución 1080, los dos ańos siguiente se adoptaron la Declaración de Nassau y la Declaración de Managua para la Promoción de la Democracia y el Desarrollo, en las que se acordó desarrollar mecanismos para proporcionar la asistencia que los Estados Miembros soliciten para promover, preservar y fortalecer la democracia representativa y se expresó la convicción de que la misión de la Organización no se limita a la defensa de la democracia en los casos de quebrantamiento de sus valores y principios fundamentales, sino que requiere además una labor permanente y creativa dirigida a consolidarla, así como un esfuerzo permanente para prevenir y anticipar las causas mismas de los problemas que afectan el sistema democrático de gobierno.

El mecanismo previsto en la Resolución 1080 se aplicó en cuatro oportunidades: Haití (1991), Perú (1992), Guatemala (1993) y Paraguay (1996). En el primer caso se trabajó en colaboración con Naciones Unidas y se recurrió a medidas tales como el no reconocimiento y el aislamiento del gobierno de facto, la congelación de activos financieros por algunos países, la suspensión de créditos y de la ayuda internacional, el embargo y finalmente la amenaza del uso de la fuerza. En los casos de Perú y Guatemala, no fue necesario recurrir a la amenaza o el uso de la fuerza, resultando suficiente la condena y presión ejercida por la OEA y la comunidad internacional para restaurar la institucionalidad democrática. Por último, en el caso de Paraguay, el mecanismo se activó para prevenir una ruptura del proceso democrático tras una amenaza de golpe de Estado por parte de un líder militar ${ }^{6}$.

Por otra parte, en la Tercera Cumbre de las Américas, celebrada en Quebec en abril de 2001, los miembros de la Organización adoptaron una cláusula democrática ${ }^{7}$ que establece que cualquier alteración o ruptura inconstitucional del orden democrático en un Estado del Hemisferio constituye un obstáculo insuperable para la participación del gobierno de dicho Estado en el proceso de Cumbres de las Américas, a la vez que se propuso la elaboración de la Carta Democrática a fin de fortalecer los mecanismos existentes para promover y defender la democracia.

Se realizaron numerosos proyectos en los que diversos actores de la sociedad civil tuvieron ocasión para intervenir con sus ideas y propuestas, mismas que, después de ser debatidas por el Grupo de Trabajo del Consejo Permanente, fueron incorporadas en la redacción del texto

6. Para un análisis de la aplicación de la Resolución 1080 puede consultarse Amaya Úbeda de Torres, Democracia y derechos humanos en Europa y en América. Estudio comparado de los sistemas europeo e interamericano de protección de los derechos humanos (Madrid: Reus, 2007), pp. 183-192.

7. Los sistemas de integración de la región -Mercosur y Pacto Andino- ya contaban con una cláusula similar desde mediados de la década de los '90. 
final. Finalmente, el 11 de septiembre de 2001 tuvo lugar la primera sesión plenaria donde fue aprobada por aclamación la Carta Democrática Interamericana.

En cuanto al contenido de la Carta Democrática Interamericana, vale resaltar que ésta no proporciona una definición de democracia, pero, aun así, logra ampliar su concepto, superando la definición mínima entendida como régimen político con elecciones libres, justas y periódicas. Este instrumento la concibe más bien como un régimen que garantiza el respeto a los derechos humanos y la subordinación de las instituciones estatales a la autoridad civil, que refuerza la pluralidad en los partidos políticos o que lucha contra la exclusión social ${ }^{8}$.

En este orden de ideas, la esencia de la Carta contiene dos ingredientes que la caracterizan: por un lado, la definición tanto de los elementos esenciales de la democracia como de los componentes fundamentales para su ejercicio, y por el otro, la reglamentación de los mecanismos de defensa colectiva de la democracia en el continente americano ${ }^{9}$. A pesar de que en los artículos 3 y 4 de la Carta no se define qué diferencia conceptualmente a los elementos esenciales de los componentes fundamentales, ambos artículos proporcionan pautas para identificar cuándo se ha producido una subversión del orden democrático y sobre cuál es su gravedad, a fin de aplicar el mecanismo de acción colectiva que resulte apropiado a cada hipótesis.

Dichos elementos y componentes podrían sintetizarse en las características de lo que actualmente define a la democracia liberal, en tanto refieren al respeto a los derechos humanos y las libertades fundamentales, la división de poderes, la representación popular, la elección de los gobernantes a través del voto universal, directo y secreto, el control jurisdiccional de la legalidad de los actos, la separación de poderes, la proscripción de perpetuación en el poder y el pluralismo partidario, entre otros. Sin perjuicio de la importancia de todo lo señalado, la Carta menciona una cuestión central que es el respeto de la libertad de expresión, pues precisamente los estándares del sistema interamericano en esta materia se desarrollaron muy acelerada y consolidadamente y será en gran medida un elemento que dividirá los gobiernos según cómo se posicionan frente a la libertad de expresión, acercándose al concepto de democracia liberal o al populismo.

Por otra parte, la Carta contempla situaciones distintas de crisis de la democracia que responden a los diferentes grados en que puede ser afectada y establece mecanismos internacionales de protección a cargo de la OEA, que comprenden: la iniciativa del propio

8. Neus Ramis, “La OEA y la promoción de la democracia en las Américas: un objetivo en construcción”, ICIP WORKING PAPERS: 2010/07 (Barcelona: Institut Català Internacional per la Pau, noviembre 2010), p. 15.

9. Pedro Nikken, “Análisis de las definiciones conceptuales básicas para la aplicación de los mecanismos de defensa colectiva de la democracia previstos en la Carta Democrática Interamericana”, Revista IIDH, n 43 (enero-junio 2006), 13-56, p. 18. 
gobierno afectado en caso de riesgo para su democracia; la iniciativa del Secretario General en casos de situaciones que puedan afectar la democracia; las sanciones en caso de ruptura del orden democrático o de una alteración del orden constitucional que afecte gravemente el orden democrático; la iniciativa de cualquier Estado Miembro en caso de que se produzca una alteración del orden constitucional que afecte gravemente el orden democrático de un Estado Miembro; la suspensión de un Estado Miembro en caso de ruptura del orden democrático; y el levantamiento de la suspensión. Estos mecanismos están visualizados de manera que en su aplicación se respete los principios de gradualidad y de proporcionalidad. Esto quiere decir que, en primer lugar, debe intentarse la solución o superación del obstáculo o alteración o ruptura del orden constitucional y en su defecto, la aplicación de sanciones colectivas a los derechos y privilegios del Estado en la Organización. Y, en segundo lugar, que la actuación colectiva debe guardar relación con la gravedad del obstáculo o alteración o ruptura del orden constitucional, conforme a lo dispuesto en los mecanismos de protección de la democracia en la Carta Democrática ${ }^{10}$.

\subsection{Los nuevos regímenes políticos y la aplicación de la Carta Democrática Interamericana}

El sistema democrático, conforme los componentes mencionados, conlleva una relación directa con el sistema de protección de los derechos humanos y supone el cumplimiento de las reglas y procedimientos acordes, tales como la independencia del poder judicial, la libertad de expresión y, fundamentalmente, el respeto de las garantías, las minorías y el pluralismo.

Sin embargo, existe un patrón emergente en el cual un gobierno obtiene el poder en elecciones democráticas, pero una vez en control del Estado ejerce su poder para ignorar, descalificar y debilitar las instituciones, valores y prácticas democráticas contempladas en sus propias constituciones y en la Carta Democrática. El modelo se basa en la acumulación y el monopolio del poder por el poder ejecutivo en detrimento de la autonomía y competencia de los demás poderes y utiliza mecanismos de la democracia como son las elecciones, los plebiscitos o referendos y mayorías transitorias en el poder legislativo, o en el poder judicial y electoral, para modificar las reglas de juego en su favor ${ }^{11}$.

En este contexto, los redactores de la Carta Democrática, observando que llegado el siglo actual la dicotomía entre los gobiernos militares y los civiles de elección popular es desplazada por otra más peligrosa, sinuosa, a saber, la de gobernantes electos mediante el voto democrático quienes luego, en sus ejercicios y sin que encuentren resistencias sociales pétreas, postergan

10. Carlos Ayala Corao, "Los mecanismos internacionales para la protección colectiva de la democracia en la Carta Democrática Interamericana”, en Defensa colectiva de la democracia: definiciones y mecanismos, ed. por Pedro Nikken Bellshaw-Hógg y Carlos Ayala Corao (Lima: Comisión Andina de Juristas-The Carter Center, 2006), 87-121, pp. 95 y 98. 11. Rubén Perina, "Los desafíos de la Carta Democrática Interamericana”, op. cit., p. 12. 
la experiencia de la democracia y ponen de lado la mediación de sus instituciones, deciden, para lo sucesivo, por una estrategia promotora, defensiva y renovadora de los estándares de la democracia representativa ${ }^{12}$.

De este modo, se observa que la vertiente clásica de la democracia representativa entró en tensión con las denominadas democracias participativas o directas que empezaron a adoptar los Gobiernos de Bolivia, Ecuador, Venezuela y Nicaragua, en parte para encubrir un creciente autoritarismo y la concentración de $\operatorname{poder}^{13}$, retomando la ideología clásica del populismo.

En este orden de ideas, el concepto de pueblo es central en la manera en que el populismo entiende la democracia y es construido a partir de un discurso que divide a la sociedad en dos campos antagónicos.

Ernesto Laclau, precisamente enseña que el pueblo es la forma específica de una identidad populista y se apoya en demandas populares, que pasan a constituir una subjetividad social más amplia y empiezan a conformar al pueblo. Como resultado, lo popular es imaginado como una entidad homogénea, fija e indiferenciada ${ }^{14}$, que se identifica con el todo.

Además, el pueblo va a implicar dos cuestiones: el pueblo en tanto nombre de la comunidad ("pueblo argentino") y también como parte de la comunidad (los menos privilegiados) ${ }^{15}$, configurando un escenario donde una plebs reclama ser el único populus legítimo ${ }^{16}$.

De esta forma, el pueblo no es otra cosa que una frontera de exclusión que genera una división dicotómica de la sociedad, entre un nosotros (el pueblo) y un ellos (los enemigos del pueblo). Esta idea de que la oposición está conformada por los enemigos acarrea una tendencia hegemónica muy fuerte, que a su vez lleva a conflictos sociales y políticos intensos porque la oposición también responde en términos intransigentes.

Al mismo tiempo, el populismo se apoya sobre la figura de un líder con virtudes sobredimensionadas. En su faceta humanizadora, el populismo convierte al líder en una persona que está cerca del pueblo, es de carne y hueso y por eso puede romper el protocolo y las reglas ceremoniales de la clase opresora.

12. Asdrúbal Aguiar, Calidad de la democracia y expansión de los derechos humano. Cuadernos de la Cátedra Mezerhane sobre Democracia, Estado de Derecho y Derechos Humanos, op. cit., pp. 23-24.

13. Susanne Gratius, "Diez años de la Carta Democrática Interamericana”, op. cit., p. 2.

14. Leonardo Avritzer, Democracy and the Public Sphere in Latin America (Princeton: Princeton University Press, 2002), p. 72 .

15. Paula Biglieri, "Nueva conceptualización sobre populismo en América Latina. La emergencia del kirchnerismo”, en La democracia en América Latina. Partidos políticos y movimientos sociales, ed. por Arturo Fernández y Cecilia Lesgart (comp.) (Rosario: Homo Sapiens Ediciones, 2008), 63-97, p. 69.

16. Ernesto Laclau, La razón populista (Buenos Aires: FCE, 2005), p. 108. 
La representación populista asume, así, una identidad de intereses entre el pueblo y su líder, autoerigido como el símbolo y la encarnación de la Nación. Los líderes populistas actúan como si conocieran quién es el pueblo y cuál es su voluntad, pero sus propuestas no valoraron los procedimientos de la democracia liberal por entenderlos como impedimentos para que se exprese la voluntad popular encarnada en el líder.

Si bien las elecciones limpias son la base de las credenciales democráticas del populismo, una vez que el pueblo ha votado, los populistas consideran que el electorado debe someterse políticamente al líder ${ }^{17}$. Estos líderes no se ven a sí mismos como políticos regulares que han sido elegidos por un periodo determinado, sino que se sienten portadores de misiones míticas, tales como alcanzar la segunda independencia para forjar democracias que superen los vicios de la democracia liberal.

Por estos motivos, es muy difícil la sucesión en los gobiernos populistas, ya que son gobiernos personalistas, lo cual significa que no quieren institucionalizar el propio movimiento, porque la institucionalización significa limitar el poder del máximo líder.

En particular, en el caso del peronismo y kirchnerismo argentino -como su versión más puramente populista-, es posible observar claramente las actitudes de liderazgo extremo de sus actores históricos y la construcción de la figura del pueblo argentino y la de los enemigos del pueblo argentino ${ }^{18}$.

En suma, la polarización de la sociedad y la exacerbación del rol del líder da cuenta de una completa contradicción entre el populismo y la democracia liberal, atento a que se vale de un patrón de comportamiento que termina socavando instituciones, valores y prácticas democráticas como la separación e independencia de poderes, la libertad de expresión, el Estado de derecho, las elecciones libres y justas y el respeto de las minorías o de la oposición, entre otros - todas ellas consagradas en la Carta Democrática Interamericana ${ }^{19}$.

En este contexto, desde la adopción de la Carta, la OEA ha invocado su aplicación en varias situaciones de amenaza a la institucionalidad democrática, nunca ha sido utilizada para fortalecer la democracia en países con regímenes autoritarios. Toda vez que no es el objeto de este artículo, haré una breve referencia únicamente a dos de las situaciones más ilustrativas en las que se hizo valer la $\mathrm{Carta}^{20}$ :

17. Enrique Peruzzotti, "Populismo y representación democrática”, en El retorno del pueblo. El populismo y nuevas democracias en América Latina, ed. por Carlos De la Torre y Enrique Peruzzotti (eds.) (Quito: Flacso, 2008), 97-124, p. 109.

18. Sobre este tema, recomendamos la lectura de Gino Germani, "Tradiciones políticas y movilización social en la base de un movimiento populista nacional: el peronismo argentino”, en Autoritarismo, fascismo y populismo nacional, ed. por Gino Germani, (Buenos Aires: Temas Grupo Editorial SRL, 2003), pp. 149-174; y Paula Biglieri, "Nueva conceptualización sobre populismo en América Latina. La emergencia del kirchnerismo", op. cit.

19. Rubén Perina, "Los desafíos de la Carta Democrática Interamericana”, op. cit., p. 13.

20. Otras situaciones en las que se aplicó la Carta Democrática Interamericana fueron respecto a Bolivia $(2003,2005$ y 2008), Ecuador (2005), Haití (2005) y Nicaragua (2005). 
El primer país donde se aplicó la Carta Democrática fue en el caso del golpe de Estado contra el presidente de Venezuela, Hugo Chávez, en 2002. En aquella oportunidad, la OEA calificó la situación como una alteración grave del orden constitucional y condenó los actos de violencia, fungiendo como mediador entre las partes para restablecer la plena democracia, aunque sin hacer denuncia alguna contra el creciente autoritarismo del presidente.

Luego, en 2009 se llevó a cabo un golpe de Estado en Honduras que destituyó al presidente Manuel Zelaya. Ante ello, la OEA aplicó el artículo 21, suspendiendo temporalmente a dicho país del ejercicio de su derecho de participación en la Organización. Al año siguiente, la OEA también reaccionó firmemente ante la sublevación de la policía en Ecuador que amenazó con derrocar al presidente Rafael Correa. Su resolución de septiembre de 2010 indicó una clara condena del levantamiento y la alteración del orden constitucional.

En relación a la actuación de la Corte Interamericana de Derechos Humanos, en tanto órgano jurisdiccional de la OEA, Pedro Nikken, un antiguo juez de la Corte, ha dicho que "la Carta Democrática no es un instrumento para la protección de derechos individuales, ni para remediar situaciones en las cuales el aparato del Estado, al no estar bien adecuado a la obligación a cargo de éste de garantizar los derechos humanos a todas las personas bajo su jurisdicción, acarrea violaciones a tales derechos que pueden singularizarse y resolverse independientemente, pues es esa la función que cumple el sistema regional de derechos humanos, cuando se reúnen los requisitos para tener acceso al mismo"21.

En este entendimiento, la utilización de la Carta Democrática por la Corte Interamericana es aún precaria en su jurisprudencia en materia de derechos democráticos para poder trazar con certeza los efectos reales en este espacio del sistema interamericano ${ }^{22}$. Empero, el tribunal la ha posicionado como un documento relevante en la interpretación de los derechos políticos reconocidos en la Convención Americana sobre Derechos Humanos, utilizándola como base conceptual para dar sustento a muchos de los avances en dicha materia en la región ${ }^{23}$.

Actualmente, a instancia del Estado de Colombia, se encuentra en discusión una solicitud de opinión consultiva respecto a la figura de la reelección presidencial indefinida en el contexto del Sistema Interamericano de Derechos Humanos que puede conformar un escenario ideal para que la Corte comience a delimitar los rasgos definitorios del sistema democrático y si determinados sistemas políticos están o no en contradicción con la democracia ${ }^{24}$.

21. Pedro Nikken, "Análisis de las definiciones conceptuales básicas para la aplicación de los mecanismos de defensa colectiva de la democracia previstos en la Carta Democrática Interamericana”, op. cit., p. 31.

22. Armando Salas Cruz, "La Carta Democrática Interamericana y la Corte Interamericana de Derechos Humanos", Revista Mexicana de Derecho Constitucional, n 31 (julio-diciembre 2014), 185-235, p. 235.

23. Véase, por ejemplo, el párrafo 207 de la sentencia del “caso Yatama vs. Nicaragua” y el párrafo 19 del voto concurrente del juez García-Sayán (Corte IDH. “Caso Yatama Vs. Nicaragua”. Excepciones Preliminares, Fondo, Reparaciones y Costas. Sentencia de 23 de junio de 2005. Serie C No. 127)

24. Al respecto, recomendamos la lectura del amicus curiae presentado por la ONG "Fundación para el Debido Proceso", disponible en la página web de la Corte Interamericana de Derechos Humanos. 


\section{CONCLUCIONES}

El término democracia ha sido muy utilizado, a veces de modo equivoco, dentro de la ciencia política y del derecho constitucional e internacional. Así, pese a que no existe una definición concreta en el sistema interamericano, la democracia representativa ha sido designada acertadamente por la Corte como "un 'principio' reafirmado por los Estados americanos en la Carta de la OEA, instrumento fundamental del Sistema Interamericano"25.

Esta ausencia de definición puede ser suplida a través de una interpretación de la Carta de la OEA a la luz de los derechos políticos proclamados en el artículo XX de la Declaración Americana de los Derechos y Deberes del Hombre, obteniendo una aproximación conceptual como aquella forma de gobierno que emana del pueblo a través de representantes elegidos mediante elecciones populares, de voto secreto, genuinas, periódicas y libres. Esta aproximación, no obstante, se limita al origen del gobierno democrático y no tiene presente otros elementos sustanciales a la forma democrática de gobierno, relacionada con los límites que han de imponerse al ejercicio del poder público con base en las reglas del estado de derecho y del respeto y la garantía debidos a los derechos humanos ${ }^{26}$.

En este marco, la Carta Democrática Interamericana proporciona un contexto hermenéutico particularizado que sirve de criterio interpretativo al momento de valorar las violaciones a los derechos políticos reconocidos por la CADH, y pauta para aclarar dudas conceptuales sobre la democracia. El valor de este instrumento jurídico radica, entre otras cosas, en el amplio consenso regional del que goza debido a la forma en que se elaboró, constituyendo una valiosa herramienta para la promoción y defensa colectiva de los valores democráticos en la región.

De este modo, logra materializar una antigua aspiración del continente de prevenir el menoscabo del orden democrático a través de la defensa colectiva que, en abstracto, es el esfuerzo multilateral que en común busca prevenir y proteger de forma pacífica situaciones que pongan en peligro la existencia de un principio, bien o valor determinado, al cual las partes le han otorgado relevancia fundamental para los fines y objetivos que persiguen. Lo anterior puede incluir procedimientos y mecanismos de preservación y garantía. En este sentido, la ayuda y la solidaridad son obligaciones indispensables para el buen funcionamiento de los mecanismos de defensa, y así evitar daños y desequilibrios. En resumidas cuentas, si hablamos de defensa de la democracia, también, en cierto sentido, nos estamos refiriendo a ese propósito esencial de la OEA de promover la democracia en la región, donde se inserta como una de sus principales acciones ${ }^{27}$.

25. Corte IDH. "La expresión "Leyes" en el artículo 30 de la Convención Americana sobre Derechos Humanos", Opinión Consultiva OC-6/86 de 9 de mayo de 1986, Serie A No. 6, párr. 34.

26. Pedro Nikken, "Análisis de las definiciones conceptuales básicas para la aplicación de los mecanismos de defensa colectiva de la democracia previstos en la Carta Democrática Interamericana”, op. cit., p. 19.

27. Armando Salas Cruz, "La Carta Democrática Interamericana y la Corte Interamericana de Derechos Humanos", op. cit., pp. 198-199. 
Las respuestas de la OEA ante situaciones de amenaza del orden constitucional han sido firmes contra los intentos de alterar el orden constitucional. Sin embargo, existe una ausencia de respuestas ante el autoritarismo de los gobiernos amenazados. En este sentido, la Carta refleja una clara politización debido a la división ideológica entre la izquierda y la derecha latinoamericana y en lugar de servir de instrumento preventivo a las crisis políticas y de promover las instituciones democráticas, como inicialmente fue propuesto, se ha convertido en un instrumento antigolpes y en una herramienta política que refleja una lucha de poder interna entre los 34 países $^{28}$.

Precisamente hace 15 años que el Sistema Interamericano de Derechos Humanos está en crisis porque casi la mitad de los Estados que conforman la OEA no están del todo de acuerdo con la relatoría para la libertad de expresión y los estándares que se fijaron siguiendo un modelo de democracia liberal. Sin embargo, no hay que perder de vista que no existe sistema constitucional que no tenga asegurada una vigencia si el pueblo se la presta.

Actualmente se observa que el pueblo vota directamente pensando en su líder, y no en su determinación por los electores, a los que el pueblo ni conoce ni le interesa ${ }^{29}$. En este sentido, la democracia no se acaba con las elecciones y las amenazas no se limitan a los golpes de Estado, siendo que las divisiones político/ideológicas demuestran que en la actualidad existe una gama cada vez mayor de comportamiento no democrático que exige aumentar el compromiso democrático común.

La condena a los golpes de Estado perpetrados en el continente ha sido una correcta aplicación de la Carta Democrática, pero los Estados miembros han fallado en reaccionar cuando los presidentes han utilizado los mecanismos democráticos formales para concentrar el poder y ejercieron el autoritarismo, reprimiendo a la oposición y a la sociedad civil, censurando los medios de comunicación, militarizado la sociedad y aboliendo la separación de poderes.

El populismo es más que una cuestión de liderazgo, discurso político o construcción mayoritaria, es más bien una ideología que atenta contra la democracia en el hemisferio americano. El círculo se cierra con la manipulación de los procesos electorales para asegurar la no alternancia en el poder y el continuismo del régimen, y se concreta mediante lo que se podría llamar "fraude" o "distorsión estructural", que adopta varias formas y se aplica mucho antes del día de las elecciones. Con el control que ejercen algunos gobiernos en la legislatura y el poder judicial y electoral, se manipulan las leyes electorales para cambiar aspectos

28. Susanne Gratius, “Diez años de la Carta Democrática Interamericana”, op. cit., pp. 2-3.

29. Jorge Vanossi, "El cuidado y control de las instituciones del Estado mediante el derecho", La Ley, n 22 (2021-A 25 de enero 2021), p. 3. 
estructurales del sistema político/electoral en favor del gobierno o régimen de turno y sus candidatos. Esto incluye, entre otros, la modificación de distritos electorales y las fórmulas de representación, los procedimientos para elección de candidatos y los calendarios electorales; la eliminación de limitaciones constitucionales para la reelección; la aprobación de códigos electorales que amenazan o violan principios de equidad y transparencia; la conformación de instituciones electorales con autoridades parcializadas que no actúan con transparencia ${ }^{30}$.

En esta perspectiva, uno de los componentes más importante de la democracia liberal es la no perpetuación en el poder y, es por eso que la reciente solicitud de opinión consultiva en relación a la reelección ilimitada proporciona una gran oportunidad para delimitar cómo debe ser la calidad de la democracia.

En la misma línea, el contexto actual demanda que se consideren mecanismos normativos e institucionales por fuera de los sistemas regionales para hacer frente al populismo. De este modo, uno de los mecanismos que debieran ser revisados es el de las construcciones mayoritarias. El derecho parlamentario y constitucional proporciona esta herramienta, cuya errónea utilización y manipulación conlleva el riesgo del advenimiento de la acumulación del poder legislativo y del poder ejecutivo en las mismas manos. El sistema jurídico en ocasiones exige una mayoría especial o agravada cuando no pareciera ser tan necesario, y viceversa. Entonces, es necesario armonizar este mecanismo con un sistema electoral que nos permita cubrirnos del riesgo de que la mayoría no esté capacitada para gobernar, y también, por supuesto, del riesgo de que la minoría quede inerme para poder controlar ${ }^{31}$. Al respecto, además de la rigidez de las cláusulas que prevén estos mecanismos de votación, no se ha hecho un análisis muy profundo del tema, siendo que es imprescindible fundar una doctrina consolidada en un debate constitucional con mayor jerarquía, más allá de la coyuntura política o de la opinión personal de cada uno.

El respeto al principio liberal y al principio democrático exige que se procure la limitación, separación y control de los poderes, con miras a la mejor defensa de los derechos individuales y que el gobierno de la mayoría se consagre sobre la base del sufragio universal. Para ello es necesario luchar por la solidez del principio de la soberanía del pueblo y la forma republicana de gobierno, asegurando la vigencia de las garantías democráticas en igualdad de condiciones para todas las personas.

Mientras que el contexto de treinta ańos atrás le impuso a la Corte Interamericana la tarea de garantizar la no impunidad, la coyuntura actual permite que hoy se pueda dedicar un poco más al sistema de otros derechos que no sean las violaciones sistemáticas de los

30. Rubén Perina, "Los desafíos de la Carta Democrática Interamericana”, op. cit., pp. 12-13.

31. Jorge Vanossi, “El cuidado y control de las instituciones del Estado mediante el derecho”, op. cit., p. 3. 
derechos humanos y permita, así, aumentar los alcances de los mecanismos previstos en la Carta Democrática Interamericana para preservar el orden democrático en la región.

\section{REFERENCIAS}

- Aguiar, Asdrúbal. Calidad de la democracia y expansión de los derechos humanos. Cuadernos de la Cátedra Mezerhane sobre Democracia, Estado de Derecho y Derechos Humanos. Caracas: Editorial Jurídica Venezolana, 2018.

- Aguiar, Asdrúbal. El derecho a la democracia. La democracia en el derecho y la jurisprudencia interamericanos. La libertad de expresión, piedra angular de la democracia. Caracas: Editorial Jurídica Venezolana, 2008.

- Avritzer, Leonardo. Democracy and the Public Sphere in Latin America. Princeton: Princeton University Press, 2002.

- Ayala Corao, Carlos. "Los mecanismos internacionales para la protección colectiva de la democracia en la Carta Democrática Interamericana”. Defensa colectiva de la democracia: definiciones y mecanismos, ed. por Pedro Nikken Bellshaw-Hógg y Carlos Ayala Corao, 87-121. Lima: Comisión Andina de Juristas-The Carter Center, 2006.

- Biglieri, Paula. "Nueva conceptualización sobre populismo en América Latina. La emergencia del kirchnerismo". La democracia en América Latina. Partidos políticos y movimientos sociales, ed. por Arturo Fernández y Cecilia Lesgart (comp.), 63-97. Rosario: Homo Sapiens Ediciones, 2008.

- Germani, Gino. “Tradiciones políticas y movilización social en la base de un movimiento populista nacional: el peronismo argentino". Autoritarismo, fascismo y populismo nacional. Ed. por Gino Germani, 149-174. Buenos Aires: Temas Grupo Editorial SRL, 2003.

- Gratius, Susanne. "Diez años de la Carta Democrática Interamericana”. FRIDE, Policy Brief No 61, septiembre 2011. Acceso el 15 de enero de 2021 desde https://www.flacsoandes.edu.ec/sites/default/files/agora/files/1328286471.pb_61_ carta_democratica_interamericana_1_.pdf

- Laclau, Ernesto. La razón populista. Buenos Aires: FCE, 2005.

- Nikken, Pedro. "Análisis de las definiciones conceptuales básicas para la aplicación de los mecanismos de defensa colectiva de la democracia previstos en la Carta Democrática Interamericana”. Revista IIDH, no 43 (enero-junio 2006), 13-56. 
- Perina, Rubén. "Los desafíos de la Carta Democrática Interamericana”. Estudios Internacionales, $\mathrm{n}^{\circ} 173$ (2012), 7-36. https://doi.org/10.5354/0719-3769.2012.26954

- Peruzzotti, Enrique. "Populismo y representación democrática”. En El retorno del pueblo. El populismo y nuevas democracias en América Latina. Ed. por Carlos De la Torre y Enrique Peruzzotti (eds.). Quito: Flacso, 2008, 97-124.

- Ramis, Neus. "La OEA y la promoción de la democracia en las Américas: un objetivo en construcción". ICIP WORKING PAPERS: 2010/07, Barcelona: Institut Català Internacional per la Pau, noviembre 2010.

- Salas Cruz, Armando. "La Carta Democrática Interamericana y la Corte Interamericana de Derechos Humanos". Revista Mexicana de Derecho Constitucional, n 31 (julio-diciembre 2014), 185-235.

- Úbeda de Torres, Amaya. Democracia y derechos humanos en Europa y en América. Estudio comparado de los sistemas europeo e interamericano de protección de los derechos humanos. Madrid: Reus, 2007.

- Vanossi, Jorge. "El cuidado y control de las instituciones del Estado mediante el derecho". La Ley, n 22 (2021-A 25). 


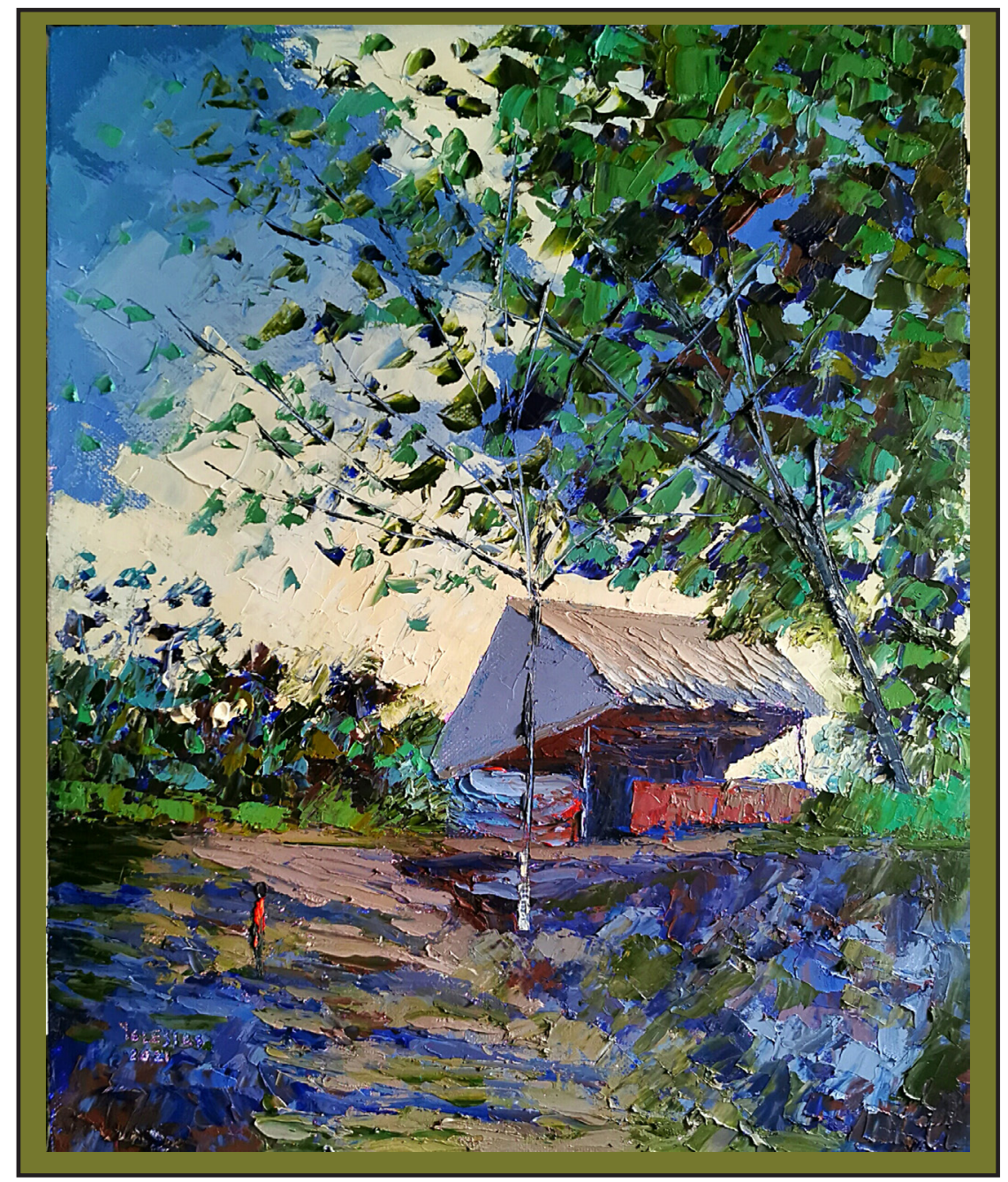

Tamshiyacu. Óleo sobre tela, $41 \times 33 \mathrm{~cm}$. Javier Yglesias Sánchez (Iquitos, Perú, 1963)

Correo electrónico: javieryglesiassanchez@hotmail.com 